\title{
Research on Computer Professional Educational Reform
}

\author{
Yanliu Nie ${ }^{1, a}$, Hexiang $\mathrm{Lu}^{2, \mathrm{~b}}$ and Liyun Wang ${ }^{3, \mathrm{c}}$ \\ ${ }^{1}$ Information Engineering Department, Zhengzhou University of Industrial Technology, Xinzheng, \\ 451100, China \\ ${ }^{2}$ Art School, Zhengzhou University of Industrial Technology, Xinzheng, 451100, China \\ ${ }^{3}$ Information Engineering Department, Zhengzhou University of Industrial Technology. Xinzheng, \\ 451100, China \\ a361045705@qq.com, b517564763@qq.com, '912725921@qq.com
}

Keywords: Promote learning through competition; Opening labs; Teaching mode; High-efficient classroom

\begin{abstract}
In this article, basing on the analysis of the short about current college computer professional, explaining the sense of promote learning through competition. In order to make it implement successfully, we can follow the aspects including courses and teaching mode, opening labs, teachers Training and school policy support. Further explaining the sense of promote learning through competition is to improve students' learning habits, raising students' interest in learning, making them learning goals clearly and realizing the pleasure of learning in order to build high-efficient classroom.
\end{abstract}

\section{Introduction}

College education goal is to make the students have job skills to meet the current social employment required, however, the current development of computer professional is rapid, but computer science education is backward [1], the quality of teaching is poor, student's computer theory is not high, the ability of operating is weak. The main reasons for this situation caused by school's hardware conditions can't meet the requirements, curriculum unreasonable, teaching methods and so on[2].Besides, the common problem among the most of the domestic college students is lack of operating environment and training opportunities. So this mode of promoting learning through competition is to improve students' learning habits, improve students' interest about learning, learning goals clearly, experience the fun of learning, to build high-efficient classroom. In recent years, our country and universities pay more attention to competition teaching. Each year the Ministry of Education and universities will hold kinds of types of competition. For the winning students to give some reward, under the same conditions the winning students have priority admission for postgraduate and priority offer when finding a job.

\section{Connotation}

Promoting learning through competition is student-centered in daily learning, through organization of a high degree of simulation and highly targeted skills competition to create a good competition environment. In fact take the skills competition as the center start a series of skills teaching activities, Checking the skills and knowledge of computer professional students need to master. By the way of competition students can consolidate the knowledge and practical application, developing practical skills to enhance the comprehensive analysis and teamwork. On the other hand, through the competition the students $t$ can be more in-depth experience of the future patterns of employment, employment orientation, not only enhance their employ ability and competitiveness, but also enhance their professional pride. 


\section{Improving of Teaching Mode}

Classroom is the main way and place of teaching knowledge, it is extremely important and must be well organized. In the teaching process, teachers should do the following aspects of classroom teaching: focus on classroom teaching, strengthen the basics, communicate frequently, paying more attention to the cultivation of students' logical thinking and ability to solve problems independently. Through enterprise project analysis, providing subject or free after making groups, using the experiments time to simulate real competition, let students accustomed to competition, like the competition.

Theory with practice is the basis of teaching, in the daily teaching process, Teacher can't just value the theory or application, But to train students the ability to integrate theory with practice. In the teaching process should actively use network resources, combining with the current situation of teaching, beside according to the conditions of social development, advanced computer technology, situation of students, social demand and so on, teacher can update the knowledge and increase the knowledge that learn by themselves[3].

Business project Analysis this new mode of project teaching has become more and more popular in many disciplines, Because through this teaching mode, students can quickly adjust to the role, applying their knowledge and enhance interest in learning, through this method students actively participate in classroom teaching process rather than passive acceptance, Also through project teaching students can clearly know the basic skills what the business need. So it is helpful to raise the employment rate.

The project selection is an important part of project teaching, the projects are selected must be real and typical, the projects must be from simple to complex, making sure that the aim of teaching is to solve problems, the knowledge students have acquired have its uses. therefore, any project can't be selected easily, the case must be selected comprehensive and Typical in order to make the case teaching effective.

Computer professional has its own characteristics, for example, most students have to learn programming language, such as $\mathrm{C}, \mathrm{C}++$, JAVA and so on.in the class of programming languages, Many teachers finished the code before class, the code are directly showed by PPT, the key code is marked, This is my helpful to improve efficiency in the classroom, but also has its disadvantages, Because the code written by teacher is finished early. During the operation is difficult to find problems, so students cannot see the process of solve the debug. This ability to solve problems is necessary for competition and work in the future. If just only give students a whole code, it is not helpful for students to understand the link between the structure of each code, this is very likely to cause students imagination beyond reality, students can read and understand, but can't solve the debug.

\section{Opening Labs}

Building a number of advanced, opening labs in order to meet the needs of society and business after deep investigation Including IOS development lab and innovation lab, robotics lab, network lab, network protocol analysis lab.

Opening labs plays an important role in practice teaching, it can be said is the source of the practical teaching.it also is the premise and basis of open laboratory construction. Open lab adapted to the high demands of modern enterprise well. Because through his career as students of university, student mainly study by themselves, only classroom cannot really develop excellent technology person. Only through the practical exercises in laboratory the carry out the job quickly after graduation, bringing benefits for the enterprise. students can develop innovation and teamwork through independent study and research at the same time. Therefore opening labs provide a good training platform for students.

The aim of Opening lab is to let student observe, thinking, find problem analyze and solve problems. But opening lab will not simply open the door and extended experimental time rather a student-centered teacher guiding teaching mode. Providing students with an independent study 
relaxed learning environment. The lab design different patterns of opening experiment due to students and teachers professional expertise. meeting the needs of the teaching maximum. The experiments can be divided into comprehensive design, research and technology innovation contest and science and technology competition and so on.

\section{Curriculum Construction Improvement}

Putting the competition standards into the curriculum standards and the programmer talent cultivation, building the body of application cultivation, each semester held a competition according to course and make competitions and certificates as one of the examination results of the course. College can set credit for competition. If a student get a good score in the competition it offset the practice course credits. For example, if the student win award in the JAVA program, you can get JAVA program curriculum design practical course credits. After each competition to establish analysis and evaluation mechanisms. Making sure results can truly reflect the effectiveness of reform.

\section{Teachers Construction}

The experienced teachers as leader young teachers as assistant, Each semester invite Enterprises outstanding professional and technical person for the students to do the orientation coach. College arrange young teacher into company to get practice with the retaining position. Currently senior art major studio system is a good practical mode of teaching, students in the studio class together with the teacher to design and implementate of practical projects. Computer professional can also study through this mode of teaching.

\section{Competition}

College Issue the relevant documents and come up with special funds, giving some material reward for award-winning students and teachers. Building special channel render the account.

\section{Conclusion}

Through the process and result of the competition, first evaluating student learning in order to check the students basic computer knowledge, skills and the practical ability. Second evaluating the quality of teaching and teaching reform of computer to found that the effectiveness of teaching reform including the error and weakness. Third achieving "process + Results +process" teaching goal ,its meaning to achieve results in the process, The teaching mode of promote learning through competition, it is helpful to arouse the enthusiasm of students' study and teacher's computer teaching reform. Finally improve the` quality of personnel training.

\section{Acknowledgements}

Henan Province university research projects focus on "big data retrieval and reconstruction in image annotation application" (No. 15B520036)

Henan Province scientific and technological projects "Vehicle road scene shadow detection and removal based algorithm" (No. 162102210119)

\section{References}

[1] Zhang Chunying. Exploration and practice of teaching reform of colleges and universities about computer [J].Education and Vocation. 2012(21):32-35.

[2] Yin Chen,Liu Meifang. Discussion classroom teaching computer built on the "promote lea-rning through competition"[J].Education and Vocation. 2015(06):174. 
[3] Gan Jianhou. The research of network and class combination about computer professional [J].Computer Education. 2006(02):31-33.

[4] Xiao Haihui. New education model curriculum about combine case guidance and task [J].Journal of Qinghai Junior Teachers' College. 2008(05).

[5] Luo Yaojun. curriculum designed based on projects and modular [J].Vocational \& Technical Education Forum.2009(04):22-23.

[6] Zeng Chunxian. Promote learning through competition, promote competition through learning, promote training through competition [J]. Guangxi Journal of Light Industry. 2009 (06).

[7] Li Juan. Promoting Reform by promote learning through competition, promote competition through learning [J].Science and technology talent market. 2009 (12).

[8] Zhang Xiuqin. Promote learning through competition, promote competition through learning to To enhance the quality of education [J].Ning Xia educaiton. 2009(03).

[9] Li Jiyun, Zhu Guo zhi. Establishing innovative talents teaching environment [J].Computer Education 2008(09).

[10]Wang Xiaodong, Zhang Chenjing.“Application of Inverted classroom teaching model in U niversity" [J]. Infromation technology education in China.2014(8):46 